\title{
Acesso à tecnologia biomédica: perspectiva bioética dos enfermeiros portugueses
}

\section{Resumo}

Atualmente, as sociedades industrializadas são caracterizadas pela diminuição da taxa de natalidade, enveIhecimento populacional e aumento das doenças crônicas e degenerativas. Verifica-se incremento nos gastos do setor saúde, colocando problemas de financiamento. Conceitos como avaliação tecnológica em saúde e implementação de critérios de alocação de recursos são apontados como hipóteses de resolução desse problema. Com os objetivos de identificar e analisar os princípios éticos e os fatores relacionados com a política de saúde, que podem limitar ou não a decisão de acesso à tecnologia biomédica, foi realizado um survey. Concluímos que os enfermeiros consideram que deve ser realizada avaliação tecnológica em saúde, bem como uma avaliação dos resultados decorrentes de sua utilização. A universalidade no acesso e a igualdade de oportunidades devem ser garantidas. O acesso à tecnologia deve ser decidido pelos profissionais fundamentando o paternalismo e o racionamento implícito. Refutam a prática da distanásia. Palavras-chave: Tecnologia biomédica. Alocação de recursos. Equidade. Paternalismo.

\section{Resumen}

\section{El acceso a la tecnología biomédica: perspectiva bioética de los enfermeros portugueses}

Actualmente las sociedades industrializadas se caracterizan por la disminución de la tasa de natalidad, población envejecida y aumento de enfermedades crónicas y degenerativas. Anualmente se constata un incremento en los costes del área de la salud, atendiendo a problemas de financiación. Se apunta a la evaluación tecnológica en salud y a la implementación de criterios de gestión de recursos como las opciones para resolver este problema. Nuestros objetivos fueron identificar y analizar los principios éticos y los factores relacionados con la política de salud, que pueden limitar o no la decisión de acceder a la tecnología biomédica, realizando para ello un survey. Concluimos que los enfermeros consideran que se debe realizar una evaluación tecnológica en salud y del mismo modo una evaluación de los resultados obtenidos de su aplicación. Se deben garantizar tanto la universalidad en el acceso como la igualdad de oportunidades. El acceso a la tecnología debe ser decidido por los profesionales fundamentando el paternalismo y el racionamiento implícito. Objetan la práctica de la distanasia.

Palabras-clave: Tecnología biomédica. Asignación de recursos. Equidad. Paternalismo.

\begin{abstract}
\section{Access to biomedical technology: bioethics perspective of Portuguese nurse's}

Nowadays, industrialized societies are characterized by the lower birth rate, increase in ageing population and increase in chronic and degenerative diseases. An increase in health care expenditures is seen, observing financing issues. Concepts such as health care sector technological assessment and the implementation of criteria for resource allocation are seen as possibilities for solving this problem. Aiming at identifying and addressing the ethic principals and other factors related to health care policy, that might or not limit the decision to have access to biomedical technology and for this purpose, a survey was done. We concluded that nurses consider that health technology assessment should be carried out, and so should an evaluation of the results arising from their use. The universality of access and equality of opportunities must be guaranteed. Access to technology should be decided by the professional, justifying the paternalism and implicit rationing. They refute the practice of dysthanasia.

Key words: Biomedical technology. Resource Allocation. Equity. Paternalism.
\end{abstract}

Doutoranda jferreiraeana@sapo.pt - Faculdade de Medicina da Universidade do Porto, Porto, Portugal.

Correspondência

Rua de Camões, 292, 4505-078. Argoncilhe, Portugal.

Declara não haver conflito de interesse. 
O avanço no conhecimento científico e tecnológico tem marcado as sociedades mais desenvolvidas, repercutindo nos mais diversos níveis (cultural, social, econômico, financeiro, político) e em diferentes áreas, entre as quais a da saúde. Concomitantemente, essas mesmas sociedades, fruto do progresso civilizacional, apresentam características com reflexos a curto e longo prazo, quais sejam: a diminuição da taxa de natalidade, o aumento da esperança média de vida, o envelhecimento populacional e o aumento das doenças crônicas e degenerativas. A indústria e as empresas, por meio da publicidade, tentam vender o mito da longevidade, saúde perfeita, corpo perfeito e eterna juventude, potenciando o fenômeno da disease mongering definido como a mercantilização da doença que amplia as fronteiras das enfermidades e faz crescer o Mercado para todos aqueles que vendem tratamentos ${ }^{1}$.

Este fenômeno surge da facilidade com que nos dias de hoje se criam necessidades nas populações, levando-as a consumir recursos que muitas vezes não são necessários ou não são os mais indicados. Associando todos esses fatores, temos componentes suficientes para que os gastos no setor saúde aumentem exponencialmente, o que também é potenciado pelo desperdício e pelos erros de gestão. Este cenário ocorre numa época de crise global que não atinge apenas a Europa e Portugal em particular, mas também outros países. Assim, o acesso aos cuidados de saúde com base numa justa distribuição de recursos, igualdade de oportunidades e mantendo padrões de garantia de qualidade no atendimento pode ser colocado em causa, sem desconsiderar a vertente do financiamento do sistema de saúde, determinante em todo este processo.

A justiça distributiva como princípio ético pressupõe equidade na alocação de recursos. Porém, a operacionalização deste princípio é difícil, basta para o efeito considerarmos as diferentes correntes filosóficas que the estão associadas e que apresentam diferentes propostas para interpretar o conceito de justiça. A teoria libertária defendida por Nozick ou Engelhardt dá primazia ao bem individual; Bentham e Mill, mentores do utilitarismo, defendem a utilidade efetivamente demonstrada; Rawls, baseado no conceito de "contrato social", defende a igualdade de oportunidades; Callahan destaca o bem comum e Daniels aplicou à área da saúde a doutrina rawlsiana no sentido de defender uma alocação de recursos com base numa igualdade de oportunidades. Não tem sido fácil estabelecer critérios para garantir o princípio aristotélico de "tratar igual os iguais e desigual os desiguais", assegurando a prática de uma equidade horizontal e uma vertical.
As sociedades diferem no modelo de financiamento dos seus sistemas de saúde, assim, nas sociedades que contam com um serviço nacional de saúde de financiamento público, a escassez de recursos determina que a "necessidade" seja a base para a disponibilização dos mesmos. Tal situação contrasta com as das sociedades em que a capacidade do cidadão para pagar é o fator que determina o acesso aos recursos, como acontece nos Estados Unidos da América (EUA) ${ }^{2}$. Essas diferentes bases de acesso consideradas apenas se justificam porque no mercado da saúde não existe preço para regular a oferta e a procura, agravado pelo fenômeno da procura induzida pela oferta, surgindo então a necessidade de priorizar e/ou racionar porque a procura de cuidados de saúde não condicionada pelo preço enfrenta uma oferta de cuidados de saúde condicionada por considerações de custos. Sob estas condições a procura pelos serviços de saúde suplantará sempre a sua oferta ${ }^{3}$. Neste âmbito, podemos definir priorização dos cuidados como escolhas hierarquizadas entre alternativas de cuidados disponíveis, dentro dos limites de recursos do sistema ${ }^{4}$, e racionamento como uma política implícita ou explicita que restringe medidas específicas de cuidados de saúde, fundamentada pelo fato de que os custos são proibitivos para o sistema de saúde e a sociedade ${ }^{4}$.

Diversos teóricos apontam vários aspectos como forma de resolver o problema da distribuição dos recursos. Conceitos como avaliação tecnológica biomédica e priorização/racionamento de cuidados com base em variados critérios são hipóteses de resolução, ao mesmo tempo que se pretende garantir equidade no acesso e eficiência nos resultados. De maneira geral, a problemática do racionamento pode ser considerada em três vertentes: o que racionar, quem decide o racionamento e como racionar. O que priorizar deve depender de uma avaliação tecnológica, a qual pode envolver diversos métodos, como por exemplo o recolhimento de dados primários, métodos integrativos ou de síntese, análise econômica ${ }^{5,6}$, medicina baseada em evidência e a elaboração de guidelines ${ }^{7-9}$.

Quem decide a priorização? O público, os políticos, os profissionais de saúde, os gestores, os doentes? Que fatores devem ser considerados? Idade, qualidade de vida, diagnóstico, prognóstico ou o papel social do indivíduo? Geralmente são levados em conta dois tipos de racionamento: o implícito e o explícito. O racionamento implícito é um processo fechado, pouco transparente, discriminatório, situado ao nível dos prestadores e avaliando caso a caso. $\mathrm{O}$ racionamento explícito é um processo aberto à 
sociedade, mais transparente e situado ao nível dos governantes $^{10-13}$.

Callahan considera que o racionamento deve ser realizado fora da esfera médica e dos doentes, baseado em critérios transparentes e resultantes de deliberação democrática: $O$ ponto-chave é que as decisões de racionamento devem ser tomadas ao nível político e não caso a caso ${ }^{14}$. Outros autores consideram ainda que o racionamento explícito, ao situar-se ao nível dos governantes, não deve limitar a liberdade do exercício da medicina e deve respeitar a heterogeneidade de quem necessita aceder aos recursos ${ }^{10,13}$. Geralmente nos sistemas de saúde públicos a decisão de acesso aos recursos recorre a critérios implícitos ${ }^{10}$. A literatura registra que os profissionais de saúde também preferem o modo implícito de racionamento, em vez do explícito ${ }^{15-17}$.

Sabik e Lie ${ }^{18}$ publicaram estudo sobre a experiência do racionamento explícito em sete países (Noruega, Suécia, Israel, Holanda, Dinamarca, Nova Zelândia, Reino Unido) e no Estado de Oregon (EUA). Na prática, o estudo demonstrou que todos os sistemas de saúde enfrentam problemas de justiça e eficiência no estabelecimento de prioridades para alocação de recursos. Diversos estudos têm sido realizados com a finalidade de determinar quem deve decidir o racionamento e como racionar os recursos, destacando-se algumas conclusões:

1) O público quer ser envolvido no processo de decisão, mas apenas com papel consultivo e não decisivo $^{2,19}$;

2) É delegado aos médicos o processo de decisão ${ }^{2,19-21}$;

3) A idade é fator fundamental a ser considerado no processo de decisão ${ }^{22,23}$, seja ao ter como base o argumento "justa temporada" (fair innings) ${ }^{24,25}$ ou ao ser considerada em conjunto com outras determinantes como qualidade de vida, diagnóstico e prognóstico ${ }^{20,21,26}$;

4) Quem tiver doenças resultantes de hábitos de vida pouco saudáveis, não deve ser priorizado ${ }^{21}$;

5) Jovens que trabalhem podem ser prioriza$\operatorname{dos}^{20,21}$.

6) Velhos dementes, institucionalizados, não devem ser priorizados ${ }^{27}$.

\section{Método}

Considerando o tema subjacente a este trabalho de investigação - os fundamentos bioéticos (neste trabalho representados pelos princípios éticos e política de saúde) que devem estar na base de acesso à tecnologia biomédica -, torna-se fundamental especificar e delimitar o estudo, identificando o problema. Assim, com base na pesquisa efetuada é considerado que a priorização dos cuidados (os quais, por seu lado, encerram a problemática do acesso à tecnologia biomédica) deve ser realizada e diversos aspectos podem ser adotados para a sua implementação.

Haja vista que a tecnologia biomédica é fator de despesa e que Portugal não tem uma cultura de avaliação tecnológica biomédica, existem poucos estudos relativos a este assunto adaptados à realidade portuguesa. A inquietação acerca do tema que ensejou este trabalho surgiu de uma enfermeira e, por isso, o estudo foi dirigido a este públicoalvo, formulando-se o problema do seguinte modo: "Como percebem os enfermeiros o acesso à tecnologia biomédica sob o ponto de vista bioético?". Pretendeu-se atingir os seguintes objetivos:

- identificar os princípios éticos e os fatores relacionados com a política de saúde, que podem limitar ou não a decisão de acesso à tecnologia biomédica;

- analisar os fatores (relacionados com a política de saúde ou com os princípios éticos) que vão estar na base das percepções referidas.

Este estudo pretende saber a opinião dos enfermeiros, para na prática contribuir com uma sensibilização nestas matérias, uma participação social mais crítica, desenvolvendo paralelamente o conhecimento na área das ciências sociais. Com base no referencial teórico e na problemática enunciada foram formuladas as seguintes questões de orientação, que incluem as variáveis em estudo:

- pelo fato de uma tecnologia estar disponível deve ser usada em todos os doentes para os quais tem indicação?

- relativamente ao doente, será que o diagnóstico, prognóstico, idade e qualidade de vida são passíveis de determinar o acesso à tecnologia?

- o sucesso não previsível da intervenção deve ser critério para decisão?

- a análise econômica da tecnologia deve ser critério para decisão?

- para decidir será importante considerar os interesses da instituição, da sociedade, dos profissionais, dos políticos ou da indústria?

- a vontade do doente e/ou família deve ser critério para a decisão? 
- se não deve ser usada em todos os doentes, quem deve decidir a seleção?

- todos devem continuar a ter acesso a todos os cuidados de saúde?

- será que os cidadãos que não prezam a sua saúde devem aceder à tecnologia numa base de igualdade de oportunidades?

- o pagamento dos cuidados de saúde deve manter-se nos moldes atuais ou ser mudado?

- a utilização da tecnologia deve estar dependente de guidelines e da medicina baseada em evidência?

- deve existir algum tipo de avaliação prévia dessa tecnologia?

- relativamente aos enfermeiros, será que o sexo, a idade, o estado civil, as habilitações acadêmicas e profissionais, as funções que desempenham, o tempo de exercício profissional e o perfil religioso influenciam o seu posicionamento?

- o bem individual e o bem comum influenciam a decisão de acesso à tecnologia?

No que se refere às opções metodológicas tomadas, e considerando os procedimentos técnicos adotados, os objetivos, a forma de abordagem do problema e a sua natureza, o estudo realizado é do tipo descritivo-exploratório, quali-quantitativo, porque simultaneamente queremos compreender a opinião dos enfermeiros (vertente qualitativa) e a relação estabelecida entre as variáveis consideradas no estudo (vertente quantitativa). O levantamento foi disponibilizado online por meio do site da Ordem dos Enfermeiros, encontrando-se presentemente inscritos 64.535 enfermeiros.

A amostra é do tipo não probabilística por conveniência, constituída por 506 enfermeiros. Este tipo de amostra é mais fácil de ser obtido, mas limita a generalização dos resultados pois não há garantia da representatividade da população-alvo. Os dados foram colhidos utilizando questionário de opinião (onde foram feitas afirmações em vez de perguntas), com base em escala de Likert. A escala era constituída por uma pontuação de 1 (discordo completamente) a 10 (concordo completamente). As afirmações foram agrupadas considerando duas principais dimensões: a "política de saúde" e os "princípios éticos". Em todas as afirmações possíveis consideramos a bivalência entre o "poder" e o "dever", com base na questão se "tudo o que se pode fazer, se deve fazer".

Assim, na primeira dimensão designada por "política de saúde", atendemos a aspectos como: quem deve decidir o acesso à tecnologia (profissionais, políticos, cidadãos, instituições, indústria); como deve ser decidido o acesso (com base na idade, diagnóstico, prognóstico, qualidade de vida, status social, interesses dos intervenientes); a que aceder, considerando métodos de avaliação tecnológica, resultados decorrentes da utilização, manutenção ou não do financiamento do sistema de saúde em vigor e a universalidade no acesso. Na segunda dimensão, relativa aos "princípios éticos", consideramos: a eutanásia; a distanásia e futilidade terapêutica; a ortotanásia; o adiar da morte; a beneficência e a não maleficência; o paternalismo médico, a autonomia do doente versus família, a justiça distributiva e o conflito do bem individual versus o bem comum.

O tratamento estatístico dos dados foi feito pelo programa SPSS 17,0 . No processamento e análise dos dados obtidos foi utilizada a estatística descritiva para caraterizar a amostra. A análise fatorial exploratória foi aplicada para identificar as variáveis latentes. A consistência interna dos fatores foi avaliada pelo alfa de Cronbach.

A análise foi complementada por técnicas não paramétricas: teste de Mann-Whitney, teste de Wilcoxon, teste de Kruskal-Wallis. Foi também usado o coeficiente de correlação de Spearman nas medidas de associação para variáveis ordinais.

\section{Resultados}

No que respeita à caracterização da amostra, obteve-se os seguintes resultados:

- maioritariamente feminina, na ordem dos $79,4 \%$;

- mais de $50 \%$ dos enfermeiros da amostra apresenta idades compreendidas entre 22 e 37 anos, o que reflete a existência de equipes jovens;

- a maioria dos enfermeiros é casada e católica;

- a maioria dos enfermeiros está ligada ao exercício prático da profissão $(86,8 \%)$ e os restantes $13,2 \%$ desenvolvem atividades na área de gestão;

- com formação pós-base (especializações, pósgraduações, mestrados) encontramos $43,3 \%$ dos enfermeiros, tendo os restantes $56,7 \%$ a formação base;

- o tempo de exercício profissional apresenta a mediana de 11 anos;

- relativamente à área de atividade, $50,6 \%$ dos enfermeiros pertencem à área cirúrgica e de cuidados intensivos, seguida pelos enfermeiros da área médica, com $23,9 \%$. 
Considerando que as afirmações (ou itens) que constituíam o questionário eram em número elevado e representavam opiniões, recorreu-se à análise fatorial, de forma a determinar as variáveis latentes (ou fatores) subjacentes em cada dimensão. Na primeira dimensão, designada por "política de saúde", das 36 afirmações consideradas três foram excluídas por não terem peso estatístico e 33 foram agrupadas em seis fatores:

1) Avaliação tecnológica - a escolha do termo resulta do fato de subjacente ao agrupamento das variáveis se encontrarem aspectos relacionados com a avaliação tecnológica biomédica;

2) Sobrevida do doente - esta designação surgiu porque o diagnóstico, o prognóstico e a qualidade de vida podem sugerir a possibilidade de previsão da sobrevivência do doente e contribuir para decidir o acesso à tecnologia na perspectiva de política de saúde;

3) Como racionar o acesso à tecnologia - esta terminologia advém do fato de as variáveis agrupadas poderem ser usadas como critério de racionamento no acesso à tecnologia numa perspectiva de política de saúde;

4) Universalidade no acesso - este termo prendese com aspectos relacionados com o financiamento dos cuidados de saúde e com a garantia de acesso de todos os cidadãos;

5) Resultados da utilização tecnológica - a opção por este termo está relacionada com as variáveis agrupadas que nos direcionam para aspectos relativos à utilização da tecnologia e, em particular, os resultados daí decorrentes;

6) Quem decide acesso - esta designação está relacionada com os interesses que alguns intervenientes no processo de acesso à tecnologia possam apresentar numa perspectiva de política de saúde.

Na segunda dimensão, relativa aos "princípios éticos", das 20 afirmações consideradas duas foram excluídas por não terem peso estatístico e 18 foram agrupadas em seis fatores:

1) Distanásia - a escolha deste termo resulta do fato de subjacente ao agrupamento das variáveis se encontrarem aspectos relacionados com a obstinação terapêutica e consequentemente o fomentar da distanásia decorrente do uso da tecnologia;

2) Justiça distributiva - "o que dar", esta designação surgiu porque a junção das variáveis direciona para os recursos que devem ser ou não dados a todos ou apenas a alguns;

3) Autonomia no acesso - esta terminologia advém do fato de as variáveis agrupadas estarem relacionadas com o exercício da autonomia no acesso à tecnologia, sem indicação do uso dessa mesma tecnologia;

4) Justiça distributiva - "quem decide", este termo prende-se com aspectos relacionados com a decisão de acesso à tecnologia numa perspectiva de justiça e considerando alguns dos intervenientes no processo;

5) Paternalismo/beneficência - a opção por este termo está relacionada com as variáveis agrupadas que direcionam para aspectos relativos à tomada de decisão por parte dos profissionais tendo por base o que consideram ser o melhor para o doente;

6) Bem comum/bem individual - esta designação advém de terem sido agrupados os dois itens referentes ao bem individual e ao bem comum, numa vertente de priorização.

$O$ teste de Mann-Whitney considerou o valor de $\mathrm{p}$ para duas amostras independentes, perante os valores da média e do desvio padrão dos fatores e as seguintes variáveis: sexo, estado civil, formação base e pós-base, ter ou não religião, exercer na área da gestão ou na prática de cuidados. O teste de Wilcoxon considerou o valor de $p$ para duas amostras emparelhadas, perante os valores da média e do desvio padrão da diferença entre o "poder" e o "dever" nas afirmações relativas ao "diagnóstico", "prognóstico", "qualidade de vida" e "opinião do profissional". o teste de Kruskal-Wallis considerou o valor de $p$ para seis amostras independentes, perante os valores da média e do desvio padrão dos fatores e as áreas de atividade onde os enfermeiros exercem o trabalho: internamento médico, internamento cirúrgico, cuidados intensivos/intermédios, urgência, bloco operatório e outros). Foi também usado o coeficiente de correlação de Spearman nas medidas de associação para variáveis ordinais (correlacionou os 12 fatores obtidos entre si e os fatores com as variáveis idade e tempo de exercício profissional).

Todas as variáveis demográficas como o sexo, idade, estado civil, habilitações acadêmicas/profissionais, funções atuais, tempo de exercício profissional e área de atividade demonstraram influência no estudo, à exceção da religião.

\section{Discussão}

A avaliação tecnológica biomédica foi fator transversal, com peso estatístico em todas as vertentes analisadas; os enfermeiros concordam que 
seja realizada, o que corrobora a importância que a literatura the atribui. Ter em consideração os resultados da utilização tecnológica foi também um fator estatisticamente significativo na maioria dos aspetos considerados, pelo que conjuntamente com a avaliação tecnológica podem validar as decisões que em política de saúde sejam tomadas acerca de que tecnologia utilizar.

A necessidade de fundamentar as decisões em matéria de tecnologia a disponibilizar deve ser uma preocupação política na atualidade. Barros diz que $a$ inovação tecnológica permanente coloca o desafio, também ele constante, de saber quando deve ser adotada e utilizada... Daqui decorre a necessidade de uma avaliação criteriosa da adoção dessas novas tecnologias e da decisão da sua utilização em cada caso particular ${ }^{28}$.

Ao correlacionarmos os 12 fatores entre si de acordo com o coeficiente de Spearman obtivemos a opinião dos enfermeiros sobre a situação em análise. Os enfermeiros discordam que o uso da tecnologia fomente a distanásia. Ao avaliar a tecnologia e ao considerar seus resultados é expectável que a distanásia não seja pretendida, não só pelo sofrimento que causa ao doente, mas também pela utilização desnecessária de recursos, sem benefícios e com custos elevados a diferentes níveis (pessoais, familiares, sociais, econômicos).

Convém, contudo, lembrar que a tecnologia, por si só, não pode ser responsabilizada pela prática da distanásia, porquanto depende do bom ou mau uso que lhe dão. $O$ que se espera é que os profissionais, quando a utilizam, sirvam aos melhores interesses do doente com base nos princípios da beneficência e não maleficência, avaliando os resultados que obtêm com a sua utilização e sabendo parar quando tal se demonstrar indicado, isto é, o tratamento se revelar fútil.

Como aponta Pessini: A vida humana é um bem fundamental, mas não um valor absoluto. Esta tradição procura o resgate da dignidade humana que integra a morte na vida. A negação da morte abre as portas para a obstinação terapêutica. Existe uma forte consciência de limite de investimentos terapêuticos. Daí nascem a sabedoria e a necessidade de discernimento de quais sejam os investimentos terapêuticos que não honram a dignidade do ser humano ${ }^{29}$.

Os enfermeiros concordam com a decisão de acesso à tecnologia com base em indicadores da sobrevivência do doente, tais como o diagnóstico, o prognóstico e a qualidade de vida, mas refutam que situações de doenças crônicas, doenças raras, fase terminal, determinadas patologias ou a idade sirvam de justificativa para limitar essa mesma decisão. Quando os enfermeiros discordam que as situações referidas limitam o acesso à tecnologia provavelmente vislumbram uma forma de discriminação.

Essa discriminação pode resultar do fato de esses indivíduos não serem produtivos, serem consumidores de recursos escassos e dispendiosos e poderem ser encarados como um "fardo" para a sociedade. Porém, se associarmos esses critérios a aspectos como o diagnóstico, prognóstico e qualidade de vida, aceitos pelos enfermeiros, talvez já não tenham que ser considerados discriminatórios, mas espera-se que configurem uma decisão justificada nos princípios éticos e no respeito pela dignidade humana.

$\mathrm{Na}$ fundamentação teórica, a idade do doente é apontada como critério importante para racionar o acesso à tecnologia. Autores como Daniels e Callahan consideram que a idade é fator individual, que deve pesar sob o ponto de vista social. Diminuir a morte em idades jovens e não prolongar a vida dos velhos, mas sim aliviar o sofrimento, são conceitos que atendem ao bem comum, tendo por atenção o bem individual.

Hans Jonas também defende que os velhos devem dar lugar aos novos, porque se suprimíssemos a morte suprimiríamos também a procriação: Neste começar uma e outra vez, que só se pode conseguir através da troca de uma e outra vez acabar, poderia muito bem radicar a esperança da humanidade, seu mecanismo de defesa para não cair no tédio e na rotina, sua oportunidade de preservar a espontaneidade da vida ${ }^{30}$.

De acordo com Jonas, a existência de um mundo de velhos, sem juventude, apenas levaria à acumulação de experiência prolongada, não permitiria o privilégio de contemplar o mundo pela primeira vez, deslumbrar-se diante do desconhecido, ter a curiosidade própria das crianças e, dessa forma, tornar possível que o conhecimento progrida numa busca permanente, numa sede constante de querer saber cada vez mais, como se nunca tivéssemos ultrapassado a fase do "porquê?".

Igualmente, Maynard e Williams ${ }^{23}$, com o argumento do "fair innings", justificam o racionamento com base na idade. Parece-nos perante o exposto que o prolongamento da velhice não deve ser objetivo a atingir, mas a realidade confronta-nos com o contrário, pois o tempo médio de vida aumenta, o número de nascimentos diminui, cresce o número de velhos na sociedade, intensificando o problema das doenças crônicas e degenerativas. Os enfermei- 
ros discordam que a idade seja fator determinante para aceder à tecnologia, mas parece-nos que esse fator, ao ser associado às doenças raras, doenças crônicas, patologias e fase terminal como não devendo ser limitativas na decisão de acesso, apenas está a salvaguardar a igualdade de oportunidades e a possibilidade de conjugar com outros fatores para, em conjunto, decidir sobre o acesso à tecnologia.

Outro questionamento pretendia averiguar se o acesso à tecnologia deve depender dos interesses das instituições, dos profissionais, da indústria promotora ou dos políticos. Os enfermeiros discordaram dessa perspectiva. Igualmente discordam que, sob o ponto de vista da justiça distributiva, possam ser os cidadãos, os gestores das instituições ou os políticos quem decida o que dar e a quem dar em matéria de saúde. Contudo, concordam que para se ter acesso à tecnologia a opinião do profissional seja considerada, tendo por base o melhor para o doente. Nesse posicionamento encontramos a validação do exercício do paternalismo, reforçando a responsabilidade de as decisões em matéria de saúde ficarem a cargo dos profissionais.

Os enfermeiros concordam com a universalidade no acesso à tecnologia, a qual também deve considerar os resultados de sua utilização e a opinião do profissional com base no que for melhor para o paciente. Em matéria de justiça distributiva, os entrevistados concordaram de forma pouco vincada com o dar tudo a todos. Isto pode decorrer do fato de não existir opinião formada entre essa classe profissional quanto ao que seja a justa distribuição dos recursos, sobre o que se deve dar e a quem se precisa dar.

As questões relativas ao financiamento dos serviços de saúde com possibilidade de manter ou mudar o modo de financiamento não foram avaliadas porque não tiveram peso estatístico. Podemos especular que isto resulta do fato de os enfermeiros não considerarem ter pensado noutro tipo de financiamento, ou então pensaram no assunto, mas não conseguiram ter opinião concreta sobre o que mudar.

Igualmente, não teve peso estatístico a possibilidade do cidadão que não preza a sua saúde não aceder à tecnologia em igualdade de oportunidades. Possivelmente as opiniões dispersaram-se entre os que consideravam que a responsabilização pessoal devia pesar na decisão de acesso aos cuidados de saúde pagos com o dinheiro público e os que consideravam que, tendo por base a liberdade de decisão individual, tal atitude não deve ser limitadora de acesso aos cuidados.
No que tange à questão da vontade do doente e/ou família ser considerada para a decisão, os enfermeiros entendem que quando não há indicação não deve haver acesso, mesmo se o tratamento for custeado pelo paciente. Tal posição parece deixar patente a prevalência dos princípios da beneficência e não maleficência sobre o da autonomia, evitando a ocorrência da futilidade ou desperdício, ainda que estes aconteçam como consequência do exercício da autonomia do doente ou da vontade da família. Demonstra, também, que os enfermeiros consideram que tomar como parâmetro unicamente a vontade da família é sempre considerada decisão complicada, pois não se deve esquecer que pode não ser isenta de conflito de interesses. $O$ acesso à tecnologia, quando esta não tem indicação e sobretudo em situações de tratamento, pode camuflar a necessidade de prolongar a vida do doente para preservar interesses de terceiros.

Quando os enfermeiros discordam que o doente ou a família paguem pelo acesso à tecnologia quando não tem indicação, apenas estão a considerar a perspectiva do utilizador, mas se ponderarmos o mercado da saúde e a perspectiva do fornecedor, é legítimo que consumam produtos se assim o entenderem. O principal objetivo das empresas é ter lucro, qualquer que seja o seu ramo de negócio - e o da saúde não foge a esta regra. A publicidade a produtos farmacêuticos, dispositivos médicos e meios de diagnóstico são exemplo disso, bem como o fenômeno da "mercantilização da doença" (disease mongering). Parece-nos que os enfermeiros não estão despertos para esta vertente do consumo que pode existir no mercado da saúde.

Este fato é importante pois os profissionais de saúde são agentes educadores, podendo aconselhar os cidadãos sobre o que os favorece ou não relativamente ao que é fornecido pelas empresas, isto é, desde que eles próprios não tenham conflitos de interesse na aquisição desses produtos, ou enfrentem situações de prática da medicina defensiva ou pressão de terceiros.

O fator "bem comum/bem individual" pretendia indicar qual seria a perspectiva dos enfermeiros sobre o bem mais valorizado para aceder à tecnologia biomédica, visando a justa distribuição dos recursos. Ainda que de forma muito pouco marcada, os enfermeiros concordaram com o bem individual e discordaram do bem comum. Este fato direcionanos para uma política do primado do ser humano, pois não se pode esquecer que é a pessoa singular ou individual que é portadora do sentido ético da sua existência... as finalidades da comunidade polí- 
tica e do estado são outras que não as da existência ética singular e pessoal ${ }^{31}$. Assim, em caso de conflito entre a finalidade política e a finalidade ética pessoal, é esta que deve predominar, pois não são as pessoas que servem a política, mas a política é que deve servir as pessoas.

Como refere Renaud ${ }^{30}$, essa situação não significa que o Estado não possa exigir sacrifícios às pessoas tendo em vista o bem comum entendido como bem individual, mas na prática vai representar um sacrifício consentido pelos próprios cidadãos, para proveito de outros e com base numa decisão política. Arbitrar esse dilema entre bem individual e bem comum não é tarefa fácil, sendo papel que pode ser assumido pelos vários intervenientes já referidos, como os políticos, cidadãos, indústria promotora da tecnologia em saúde, profissionais de saúde, instituições de saúde, doentes e gestores.

Considerando o quadro de crise econômica que a Europa atravessa, e em particular Portugal, a discordância dos enfermeiros relativamente ao consumo desnecessário de recursos e o dilema entre bem individual e comum espelha uma preocupação ética de equidade e futilidade, dado que os custos individuais refletem-se obrigatoriamente no coletivo, devendo, por isso, ponderar-se as decisões para garantir uma justa alocação de recursos.

Ainda segundo o mesmo autor, em muitos casos o bem das pessoas é uma outra forma de 'bem comum', no sentido de um bem partilhado por um grupo de pessoas consideradas isoladamente. Em numerosos casos, o bem comum - ou bem da instituição - encontra-se em conflito com o bem social ou bem das pessoas, não com o bem de uma pessoa, mas com o bem de várias ou de todas as pessoas consideradas individualmente. A vida econômica apresenta muitos casos deste estilo ${ }^{32}$.

Conciliar os dois mencionados bens nem sempre é possível, pelo que se espera que as decisões que tenham que ser tomadas nesse sentido consagrem o respeito incondicional pelo ser humano, quer de forma direta ou indireta, mas tendo presente que provavelmente algum "preço" deverá ser pago, isto é, entre dois males escolher o mal menor, como aconselha Aristóteles.

Os aspectos relativos à tecnologia biomédica com frequência suscitam a dúvida se tudo o que podemos fazer efetivamente devemos fazer. Essa questão tentou ser abordada no presente trabalho em relação a variáveis que podiam influenciar a avaliação dos profissionais de saúde, tais como: idade do doente, diagnóstico, prognóstico, qualidade de vida e opinião do profissional com base no que é melhor para o doente. Relativamente à idade, o "pode" foi eliminado no pré-teste, considerando os enfermeiros que a idade do doente não deve ser determinante para o acesso à tecnologia. De acordo com o teste de Wilcoxon, a qualidade de vida e a opinião do profissional "podem" e "devem" ser determinantes. O diagnóstico e o prognóstico "podem" mas não "devem" ser determinantes. Analisando esses posicionamentos, o dever enquanto imperativo para agir de acordo com a consciência ética está explícito nas respostas, porque nas situações em que o poder é reconhecido para ser praticado é acautelado pelo "dever" associado.

Os outros testes estatísticos realizados permitiram complementar a análise do estudo. A religião professada pelos enfermeiros não demonstrou influenciar o estudo. Apesar da bibliografia nada referir sobre este aspecto, o mesmo não podia ser esquecido porque a religião teoricamente integra a interioridade do indivíduo e, inclusive para os que não têm religião, fica a espiritualidade presente em todos os seres humanos. A idade e o tempo de exercício profissional influenciaram o estudo. Consideramos que o tempo e o acumular de experiências vividas podem condicionar a visão do problema em análise. O sexo demonstrou igualmente influenciar o estudo, o que pode ser devido às diferenças biológicas e genéticas inerentes, e a outros fatores extrínsecos como a educação, o papel social, a cultura e a formação, os quais poderão conduzir a formas diferentes de ver o mesmo problema.

A influência do estado civil na perspectiva dos enfermeiros sobre o acesso à tecnologia pode estar relacionada com o pensar a dois ou pensar individualmente. Dependendo da relação de proximidade que se tem com alguém na área dos afetos, a análise das situações vai ser influenciada pelas opiniões desse outro, que ao exercer o contraponto dialético pode estabelecer a diferença. Os níveis de formação (base ou pós-base), as funções que desempenham (área da gestão ou prática dos cuidados) e áreas de atividade onde as exercem também demonstraram influenciar o estudo. Mais uma vez a experiência, a formação e os conhecimentos obtidos com a formação ou com a própria experiência podem condicionar a análise das situações.

\section{Considerações finais}

Podemos constatar que os enfermeiros consideraram que a universalidade no acesso aos cuida- 
dos de saúde, a garantia da igualdade de oportunidades e a não discriminação de doentes são aspectos fundamentais a atender na decisão de acesso à tecnologia e num contexto de política de saúde. Este posicionamento enquadra-se nos pilares que fundamentam o serviço nacional de saúde português. A discriminação de doentes pode ser uma forma de racionamento explícito, mas os enfermeiros, apesar do argumento idade, estilo de vida ou outros, não o aceitaram, acrescido do fato de ser anticonstitucional em Portugal.

Um outro pilar igualmente importante é o da gratuidade desses serviços, e este aspecto presentemente está em risco pelas despesas que são geradas e pela dificuldade de financiamento que o país atravessa. Perante essa problemática, os enfermeiros não demonstraram opinião formada sobre o financiamento que deve ser adotado e se deve ser mudado. Em paralelo, a política de acesso aos cuidados tem sido "dar tudo a todos" e os enfermeiros, apesar do posicionamento pouco marcado, consideram que tal deve ser mantido. Esta situação pode refletir certo comodismo porque como tudo é facultado sem haver necessidade de limitar, torna mais fácil a prestação de cuidados pois quem tem que decidir sobre o que fazer não tem limitações. Se existissem limites os obrigava em certa medida a fundamentar as decisões tomadas, justificando os consumos daí decorrentes e responsabilizando os decisores pela relação consumo versus resultados obtidos.

A faixa etária dos inquiridos é jovem, na sua prática nunca conheceram outra realidade e, não só ao nível da formação profissional como em termos de cidadania, nunca foram sensibilizados para as questões relacionadas com o financiamento dos vários setores do país. Este fato é importante, pois os enfermeiros são prestadores de cuidados, mas também consumidores de recursos. Se nesta dualidade não conseguem ter ideias definidas sobre o que dar, a quem dar, como dar e qual a melhor forma de financiamento, essa dificuldade acentua-se com o grosso dos cidadãos, dificultando a tomada de decisão num contexto ético, mas que também se pretende democrático por meio da opinião pública.

Sob o ponto de vista de princípios éticos, o exercício da autonomia do doente não é salvaguardada mesmo que queira custear tratamentos desnecessários. Por um lado, prevalece o paternalismo, sendo a beneficência e não maleficência avaliadas segundo a visão do profissional com base no que considera melhor para o doente. Por outro, também está patente o evitar da futilidade e da distanásia, mesmo que o próprio assim o pretenda. $O$ fato de o bem individual ter primazia sobre o bem comum segue as linhas orientadoras da política portuguesa e do financiamento em vigor.

Continuamente muita tecnologia é disponibilizada, da qual os enfermeiros são utilizadores e não são chamados a participar para opinar sobre a relevância de sua aquisição. Os enfermeiros constituem um grupo profissional organizado, com saber próprio, mas também complementar e interdependente, pelo que devia ser incrementada a sua participação em comissões ou grupos multidisciplinares, nomeados, para avaliar a nova tecnologia biomédica a ser disponibilizada no mercado.

Quando uma nova tecnologia chega ao mercado, importa questionar que ganhos em saúde realmente comporta e que análise econômica foi realizada para justificar ser financiada pelo dinheiro público, tendo em conta a capacidade econômica do país. Em face disso, é essencial a existência, no nível de cada país, de entidades que realizem essas avaliações. Essas entidades devem ser idôneas e constituídas por experts com conhecimentos técnicos e científicos, sem conotações políticas e sem conflitos de interesse. Seria igualmente importante partilhar os resultados com as organizações internacionais que desde há vários anos desenvolvem esse tipo de atividade, permitindo um benefício mútuo com vistas à maximização dos resultados obtidos. Contudo, não basta a existência desse tipo de entidades, torna-se imperativo implementar mecanismos de controle efetivo e responsabilização legal, relativamente às diretrizes que porventura sejam emanadas.

Os profissionais da área da saúde deviam ser sensibilizados para esta temática do acesso à tecnologia biomédica. A promoção de discussões abertas sobre esses assuntos deviam ser ponderadas e as respectivas Ordens profissionais deviam ter papel mais ativo no assumir desta responsabilidade. Igualmente, os programas ao nível do ensino pré-graduado e pós-graduado dos cursos ligados à saúde deviam incluir ou reforçar temáticas relacionadas com essa problemática.

Não sabemos se será possível continuar a "dar tudo a todos", mas também não é esse o paradigma da justiça distributiva. Aristóteles defende que a justiça trata igual os iguais e desigual os desiguais, pelo que a justa distribuição dos bens respeita o princípio da proporção. Talvez seja fundamental repensar o que dar, a quem dar e como dar, bem como se deve ou não mudar os moldes de financiamento do serviço nacional de saúde português. Quando Kant afirma que o homem não é meio para uso de qualquer vontade, mas um fim em si mesmo, define a baliza 
onde acaba o poder e começa o dever, isto é, quando novas políticas de saúde possam vir a ser imple- mentadas há que fazê-lo no respeito pela dignidade humana e solidariedade entre as pessoas.

\section{Referências}

1. Moynihan R, Henry D. The fight against disease mongering: generating knowledge for action. PLOS Med. 2006;3(4):e191. doi:10.1371/journal.pmed.0030191

2. Pinho MM, Veiga P. Racionamento dos cuidados de saúde e a participação da sociedade: revisão do debate. Rev Port Sau Pub. 2010;28(2):119-26.

3. Pinho MM. Fórum: racionamento dos cuidados de saúde: introdução. Cad Saúde Pública. 2008;24(3):687-9.

4. Fortes PAC. Reflexão bioética sobre a priorização e o racionamento de cuidados de saúde: entre a utilidade social e a equidade. Cad Saúde Pública. 2008;24(3):696-701.

5. Szczepura A, Kankaanpää J, editores. Assessment of health care technologies: case studies, key concepts and strategic issues. England: John Wiley \& Sons; 1996.

6. Goodman C. HTA 101: introduction to health technology assessment. [Internet]. Bethesda: National Library of Medicine; 2004 (acesso 14 fev. 2011). Disponivel: http://www.nlm.nih.gov/ nichsr/hta101/hta101.pdf

7. Leys M. Health care policy: qualitative evidence and health technology assessment. Health Policy. 2003;65(3):217-26.

8. Rosenberg W, Donald A. Evidence based medicine: an approach to clinical problem-solving. BMJ. 1995;310:1.122-6.

9. Sackett DL, Rosenberg WMC, Gray JAM, Haynes RB, Richardson WS. Evidence based medicine: what it is and what it isn't. BMJ. 1996;312:71.

10. Pinho MM. Racionamento dos cuidados de saúde: problemática inerente. Cad Saúde Pública. 2008;24(3):690-5.

11. Holm S. "Socialized medicine", resource allocation and two-tiered health care: the Danish experience. J Med Philos. 1995;20(6):631-7.

12. Mechanic D. Dilemmas in rationing health care services: the case for implicit rationing. BMJ. 1995;310:1.655-9.

13. Tragakes $\mathrm{E}$, Vienonen $\mathrm{M}$. Key issues in rationing and priority setting for health care services. Copenhagen: WHO; 1998.

14. Callahan D. Rationing: theory, politics, and passions. Hastings Cent Rep. 2011;41(2):23-7.

15. Strech D, Persad G, Marckmann G, Danis M. Are physicians willing to ration health care? Conflicting findings in a systematic review of survey research. Health Policy. 2009;90(2-3):113-24.

16. Evans TW, Nava S, Mata GV, Guidet B, Estenssoro E, Fowler R et al. Critical care rationing: international comparisons. Chest. 2011;140(6):1.618-24.

17. Hurst SA, Hull SC, DuVal G, Danis M. Physicians' responses to resource constraints. Arch Intern Med. 2005;165(6):639-44.

18. Sabik L, Lie R. Prioritiy setting in health care: lessons from the experience of eight countries. Int J Equity Health. 2008;7(4). doi: 10.1186/1475-9276-7-4

19. Botelho A, Pinho MM, Veiga P. Who and how should participate in health care priority setting? Evidence from a portuguese survey. Lisboa: Universidade do Minho; 2011. (Working Paper Series; 43)

20. Mossialos E, King D. Citizens and rationing: analysis of a european survey. Health Policy. 1999;49(1-2):75-135.

21. Werntoft E, Edberg AK, Rooke L, Hermerén G, Elmståhl S, Hallberg IR. Older people's views of priorization in health care: the applicability of an interview study. J Clin Nurs. 2005;14(8b):64-74.

22. Daniels N. Justice between adjacent generations: further thoughts. Journal of Political Philosophy. 2008;16(4):475-94.

23. Callahan D. Setting limits: medical goals in an aging society with "a response to my critics". Washington: Georgetown University Press; 1995.

24. Maynard A. Rationing health care. BMJ. 1996;313(7.071):1.499.

25. Williams A. Rationing health care by age: the case against for. BMJ. 1997;314:822. doi: http:// dx.doi.org/10.1136/bmj.314.7083.822

26. Fleck LM. Just caring: in defence of limited age-based healthcare rationing. Camb Q Healthc Ethics. 2010;19(1):27-37.

27. Ryynänen OP, Myllykangas $M$, Kinnunen J, Halonen $P$, Takala J. Priorization attitudes among doctors and nurses examined by a scenario method. Int J Technol Assess Health Care. 2000;16(1):92-9.

28. Fernandes JV, Barros PP, Fernandes AC. Três olhares sobre o futuro da saúde em Portugal. Cascais: Princípia; 2011. p. 104.

29. Pessini L. Distanásia: até quando prolongar a vida? $2^{a}$ ed. São Paulo: Loyola; 2007. p. 430.

30. Jonas $\mathrm{H}$. El principio de responsabilidad: ensayo de una ética para la civilización tecnológica. Barcelona: Editorial Herder; 1995. p. 202.

31. Renaud M. A tensão entre o bem da pessoa e o bem comum. Cadernos de Bioética. 1996;11:9-16.

32. Renaud M. Op. cit. p. 15.

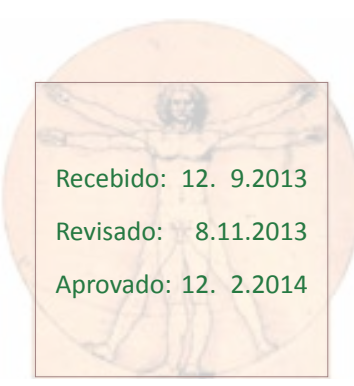

